\title{
Sobre estratégias identitárias
}

\section{Walnice Nogueira Galvão}

Resumo: $\mathrm{O}$ texto propóe que se avalie o romance brasileiro contemporâneo nos contextos nacional e internacional, Para compreender a busca de identidade desse romance, é necessário levar em conta a eclosão da biografia. Para precisar o que significa neste momento a questâo da identidade postulada por ele, é bom atentar para a fonte da preocupação com identidade, que nảo é a mesma dos séculos passados. Sugere-se que se recuse a etiqueta de "pós-colonial" quando aplicada à literatura de naçōes que são independentes há perto de dois séculos. Palavras-chave: romance brasileiro contemporàneo, questảo identitária, multiculturalismo.

Abstract: This paper intends to evaluate the Brazilian contemporaneous novels in the national and international context. However, to comprehend the efforts of these novels looking for an identity it is highly necessary to take into account the rise of the biography. At the moment, the precise meaning of the identity question presupposed in the novels points out the preoccupation intertwined with the concept of identity which may be considered different in the past centuries. It has been strongly recommended to not use the term of "post-colonial" when the conception is applied to the literature of those nations which have been considered independent for almost two centuries. Keywords: Brazilian contemporaneous novels, identity question, multiculturalism. 
Nunca se editou tanto no Brasil: o mercado editorial cresceu a tal ponto que, antes da retração dos últimos anos, elevou o país ao décimo lugar no ranking mundial. A produção atualmente é vasta e variada. Convém estudar essa produção nas linhas mestras, atendendo a que, no romance brasileiro, as estratégias identitárias diferem bastante do que se faz na Europa e nos Estados Unidos. Uma perspectiva ampliada auxiliará uma análise que leve em conta não só os temas como também as formas, para indicar as modulações que a narrativa romanesca perfaz no novo milênio.

\section{A questão identitária}

A formulação atual de uma questão identitária no romance brasileiro é insatisfatória, pelo que tem de indefinido e por se prestar a equívocos. A "identidade nacional", uma grande questão, foi construída nos escritos do século xIX a partir da Independência, até ser consolidada pelo modernismo. Romancistas, poetas e críticos deram sua contribuição, abraçando a missão de definir e elaborar uma literatura que fosse brasileira, autônoma, independente da portuguesa.

Hoje, o termo se presta a outras coisas, e quem aparenta estar com problemas de identidade são os países ricos, ante o afluxo de forasteiros pobres. Foi o que os levou a postular o "multiculturalismo" e a "diversidade cultural". Ora, esses dados no caso do Brasil são fundacionais: nós nascemos multiculturais, nós inventamos a diversidade cultural. Tal foi a questão que presidiu ao surgimento de nosso pensamento social e também de nossa literatura. Diferentemente do que se passa nesses países, seria possível apontar três níveis de outras crises de identidade.

Uma primeira, em nível de mercado ou de indústria cultural: ascensão da biografia e declínio do romance.

Uma segunda, em nível de autor: crise de identidade dos escritores que estão procurando definir quem são eles próprios e quais são seus objetivos. De saída, constatamos uma nova divisão do trabalho, pois professores universitários escrevem romances e jornalistas escrevem biografias.

E uma terceira, em nível de gênero: separação radical entre biografia e romance. Este costumava ser uma biografia ficcional, ou seja, a história de um indivíduo, de sua "aprendizagem" e "formação", de sua "educação sentimental", de suas "ilusões perdidas" Todavia, depois que o romance rejeitou seu modelo tradicional pelo

* Comunicaçāo apresentada ao congresso La Fiction Romanesque et la Problématique Identitaire, Rennes, 2006.

Teresa revista de Literatura Brasileira [10|11]; São Paulo, p. 68-78, 2010. = 71 
mundo afora, no Brasil tudo isso deslizou para a biografia, e o romance partiu em demanda de sua identidade.

\section{Prosa literária}

Consideremos primeiro o romance, ou melhor, a prosa literária.

Não há como escapar ao diagnóstico de que nossa literatura desertou o regionalismo para tornar-se metropolitana. Um tal perfil encontra sua expressão na forma dominante do romance de nosso tempo, em qualquer país, e que é o thriller ou roman noir. O thriller, como o chamam os norte-americanos, é definido pela ação violenta cheia de suspense, $\mathrm{e}$ não deve ser confundido com o policial, que é apenas uma de suas subdivisões.

Há tempos, o rei do thriller é Rubem Fonseca, prezado como contista e como romancista, louvado como jovem promissor a par com Dalton Trevisan, quando ambos surgiram. Tendendo ao despojamento, anunciou tanto o desprezo pela retórica quanto a vontade de depuração, vindo enxugar nossa prosa. No processo, encolheu o léxico, que se tornou limitado, e a gama de assuntos. Devotou-se a escrever sucinto, direto, elíptico, e como que impôs um modelo de literatura metropolitana aos leitores - que, assim afinados, passaram a achar outro tipo de prosa indulgente, derramado, beletrista - e a seus seguidores. Essas opções passariam a ser a tônica no panorama literário.

$\mathrm{Na}$ criação de personagens, pode-se dizer que o herói e protagonista-símbolo de Rubem Fonseca é o policial, assassino por opção, mesmo quando utilize codinomes elegantes como Matador ou Exterminador, que relevam da science fiction cinematográfica e televisiva. Esse homicida-herói pode ser pobre ("Feliz Ano Novo") ou rico ("Passeio noturno"), diletante ou profissional.

Foi assim que Rubem Fonseca veio a ser o correlato urbano de Jorge Amado e seu sucessor. Se Jorge Amado foi durante meio século a figura dominante da literatura brasileira, seu trono hoje é ocupado por Rubem Fonseca.

$\mathrm{Na}$ esteira dessa obra, a ascensão do thriller tornou-se a mais visível entre nós, representada igualmente por seus numerosos discípulos, entre os quais Patrícia Melo, que escolheu dedicar-se ao tipicamente policial. O thriller brasileiro banha-se em violência: esse é seu único assunto, e sobretudo quando se trata de violência urbana. Cito aqui apenas os mais conhecidos: Paulo Lins, Marcelo Mirisola, Marçal Aquino, Ronaldo Bressane, Fernando Bonassi, Marcelino Freire, Nelson de Oliveira, Luis Ruffato, Amilcar Bettega Barbosa. E ainda muitos outros, porque se trata do clima dominante. É de lamentar que a exigência de síntese colocada por esta generalização implique apagar as individualidades. 
Uma segunda tendência é aquela que se poderia chamar de neorregionalismo. Após meio século de hegemonia, o regionalismo agoniza, mas sobrevive, o que é comprovado por seus continuadores, entre os quais João Ubaldo Ribeiro, Antonio Torres, Francisco Dantas e alguns gaúchos como Tabajara Ruas e Assis Brasil (não confundir com seu homônimo do Piauí, também neorregionalista).

Uma terceira tendência é constituída pela afirmação crescente do romance histórico. Novos autores reelaboram episódios de nossa crônica, recriando-os em craveira ficcional. Podemos ler a vida pitoresca de um poeta da Bahia de antanho, como Gregório de Matos, ou a de um outro poeta mais recente, como Augusto dos Anjos; ou então uma fantasia em torno da vivência brasileira e europeia da mãe de Thomas Mann. Desse modo, nosso panorama literário se amplia, ao oferecer-nos uma meditação sobre os tempos que antecederam ao nosso. Entre neorregionalismo e romance histórico inscreve-se a obra de Márcio Souza, que fala dos fastos da Amazônia, sobretudo em Galvez, imperador do Acre, Mad Maria e na série quase completa das Crônicas do Grão Pará e Rio Negro (Lealdade, Desordem, Revolta e Derrota). Mais uma tendência que pede destaque é a obra dos pós-modernos. Estes põem em xeque a narrativa tradicional, estilhaçando-a, manejando a intertextualidade, a colagem e a montagem, em certos casos até recorrendo à ilustração. Em seu propósito de desconstruir a narrativa, revelando afinidades com o pós-modernismo, mas resguardando a peculiaridade de cada um, podem-se arrolar os nomes de Ignácio Loyola Brandão, Sérgio Sant'Anna, Caio Fernando Abreu, João Gilberto Noll, Silviano Santiago, Chico Buarque de Hollanda, Bernardo Carvalho, João Almino, Valêncio Xavier. Outra tendência dá voz às minorias, às margens, ao não hegemônico: falamos agora dos homossexuais, dos negros, das mulheres. Esta tentativa de tomar o pulso a tendências, necessariamente arbitrária, incide em recortes, lacunas, superposições. Assim, por exemplo, levaríamos em conta que alguns desses escritores não só representam a tendência em que os colocamos, como ainda podem ter participado de uma urgente tarefa internacional, qual seja a de dar voz a minorias e oprimidos. Sirva de exemplo a narrativa de perquirição do homoerotismo, em que sobressaem livros pioneiros como Stella Manhattan e Keith Jarrett no Blue Note, de Silviano Santiago; Morangos mofados, de Caio Fernando Abreu; Nove noites, de Bernardo Carvalho, e todos os de João Gilberto Noll. De modo similar, a voz dos negros se faz ouvir no presente, especialmente aquela oriunda da periferia e da favela. Em primeiro lugar, é de menção obrigatória Cidade de Deus, de Paulo Lins, que fez furor. E Capão Pecado, clara transposição do bairro suburbano paulista de Capão Redondo, do cinturão violento da metrópole, onde vive seu autor, o militante da cultura hip-hop Ferrez. Ou então uma empreitada 
ambiciosa - aliás um feito inédito em nossas letras -, como a de Ana Maria Gonçalves e seu romance Um defeito de cor, que dedica perto de mil páginas a retraçar o percurso existencial de uma escrava no Brasil, desde sua captura na África.

O resgate das reivindicações das mulheres é notável nos trabalhos universitários, com a revelação de obras escritas no feminino relegadas ao olvido, nos séculos anteriores; mas também, talvez de modo menos aparente, na ficção. Para começar, depois de uma plêiade de veteranas ainda publicando, surge no Nordeste Marilene Felinto, jornalista e escritora na ativa, que é lembrada pelo premiado As mulheres de Tijucopapo, celebração das heroínas pernambucanas que pegaram em armas para expulsar o invasor holandês. Em São Paulo, a citadina Márcia Denser destaca-se pela ousadia dos temas, ostentando a sexualidade feminina, mostrando a mulher que abre caminho no torvelinho cheio de ciladas da metrópole, contestando o poder masculino. Exemplares de sua obra são os contos de O animal dos motéis e de Diana caçadora, de títulos sintomáticos. Seus livros mais recentes são Toda prosa, que reúne inéditos e dispersos, Caos e Caim. Ao Sul, a gaúcha Letícia Wierzchowski, em $A$ casa das sete mulheres, vitoriosa minissérie televisiva em 2003, retoma a já tantas vezes explorada Revolução Farroupilha, clichê da literatura dos pagos, mas virando-o do avesso ao adotar o ponto de vista das mulheres que permaneceram em casa enquanto os homens partiam para o campo de batalha.

\section{Multiculturalismo e saga da imigração}

Exige exame mais detido, devido à voga internacional, uma última tendência, que guarda similaridades com o romance histórico, sem com ele se confundir: é a saga da imigração. Nos anos 1920 e 1930, o modernismo ocupou-se do recém-chegado contingente italiano, que vincou o tecido sociocultural, sobretudo em São Paulo. Desde então, pudemos ler romances que falam da chegada e da acomodação dos galegos espanhóis (Nélida Piñon), dos judeus (Moacyr Scliar), dos árabes (Raduan Nassar, Milton Hatoum, Salim Miguel e o refinado Alberto Mussa, que se inspira na mitologia de seus ancestrais). Aguardamos mais aportes, quando verificamos a existência de etnias relevantes já enraizadas, mas ainda sem voz literária, como a japonesa. A registrar que as obras de alguns dos supracitados transbordam dessa temática e se desenvolvem em várias direções. Há muito a fazer, mas da valia da empreitada falam tanto os resultados obtidos entre nós quanto a literatura de língua inglesa no passado, com o que já soube extrair de situações de expatriamento e de fricção interétnica. Os sul-africanos brilharam na crônica do apartheid; basta lembrar Nadine Gordimer e J. M. Coetzee, ambos prêmio Nobel.

74 - GALVÃO, Walnice Nogueira. Sobre estratégias identitárias 
Os norte-americanos elaboraram todo um ciclo de romance (e de cinema) da imigração, enquanto os ingleses fizeram o processo do imperialismo. Dentre estes últimos, ressaltam o naturalizado Joseph Conrad, Rudyard Kipling, parte da obra de Somerset Maugham, Uma passagem para a Índia, de E. M. Foster, e vários livros do funcionário colonial George Orwell, outros que não seus mais conhecidos 1984 e A revolução dos bichos. O grande cineasta inglês David Lean participou com destaque do processo, sondando o confronto entre seus compatriotas e os indianos (segundo E. M. Foster), os árabes (Lawrence da Arábia), os irlandeses ( $A$ filha de Ryan), os japoneses (A ponte do rio Kwai) etc.

Cabe observar que, na atualidade, esta tendência é uma das mais atraentes para o público do exterior, na figura do "romance étnico", que a crítica rotula indevidamente de "pós-colonial", última moda da indústria cultural cosmopolita. Mencionaremos alguns best-sellers, como $O$ deus das pequenas coisas, de Arundathi Roy, indiana que vive em seu país natal; $O$ ventre do Atlântico e Kétala, de Fatou Diome, senegalesa radicada na França; $O$ caçador de pipas, de Khaled Hosseini, afegão que mora nos Estados Unidos; Feras de lugar nenhum, de Uzodinma Iweala, nigeriano, cuja ação se situa num país africano não identificado; Intimidade e No colo do pai, do inglês de origem paquistanesa Hanif Kureishi. Uma leitura mesmo sumária mostra que os enredos giram em torno de uma ou mais cenas centrais de brutalidade escabrosa, o enredo todo construindo um suspense que vai ter seu clímax e desenlace nessa cena. Tal cena, em seu sadismo básico, tem em mira atiçar o voyeurismo do leitor, ao mesmo tempo que degrada ainda mais os nativos. Estes são apenas alguns exemplos, mas basta entrar numa livraria para encontrá-los às dezenas e às centenas. Uma vista de olhos no cinema pode ser elucidativa. No último festival de Berlim havia quatro filmes brasileiros "de favela", e um deles levou a mais alta láurea. Em meio ao troar da metralha, passou despercebida uma joia em surdina, o delicado e minimalista $M u t u m$, inspirado em Guimarães Rosa. Há que refletir sobre o seguinte: essa literatura e esses filmes oferecem aos brancos ricos o exotismo a que eles aspiram. Para reassegurá-los de sua supremacia, a atração hoje é essa, de facínoras mestiços: exotismo não só africano e asiático, mas também nosso. Assim, os países periféricos fazem literatura e cinema "de exportação", ou seja, exportam matéria-prima colonial em nível simbólico.

É curioso que, no caso dos estrangeiros mencionados, se evite colocar uma séria indagação propriamente literária: estes autores escrevem na língua do conquistador, e não nas deles mesmos. Isso ocorre também nos países africanos do antigo império colonial português, e nos relatos dos índios seja do Brasil, seja da América Espanhola. Se o assunto for a adaptação dos desterrados, o território se situará nos enclaves de estrangeiros de pele escura nos países ricos. Para os demais, o cenário comum 
é o torrão natal, sempre exótico - Iraque, Irã, Afeganistão, nações africanas, Índia, Paquistão, Brasil. Por isso, o romance que chamei de "étnico", ao contrário da saga brasileira da imigração, localiza-se de preferência em sua pátria, seu ponto de partida. No mesmo registro, o leitor já dispunha anteriormente da ficção de Salman Rushdie, autor do notório Versos satânicos, e do prêmio Nobel V. S. Naipaul, de Trinidad, ambos cidadãos da Inglaterra, mas de origem indiana.

Uma última advertência: por limitação de espaço, são citados neste panorama apenas os autores e obras mais divulgados.

\section{Biografias}

O novo biografismo nacional tem origem específica no resgate da saga da esquerda, duramente reprimida pela ditadura militar que se implantou por golpe em 1964. Depois se ramificaria em várias direções, afora a biografia: na literatura, no romance, na reportagem, no tratado histórico. E em cinema, no filme de ficção, no documentário longo, no documentário curto para TV, no telefilme e no docudrama.

Sua origem pode ser rastreada em dois outros gêneros: de um lado o memorialismo, de outro o romance-reportagem.

Ao contrário do que acontecia anteriormente, quando era tarefa de velhos, o novo memorialismo é obra de jovens - esse fenômeno curioso, gente de pouca idade a escrever memórias - os jovens da guerrilha. O primeiro, que permaneceu como uma espécie de carro-chefe, é O que é isso, companheiro? (1979), de Fernando Gabeira. Encontra-se nesse memorialismo uma discussão político-ideológica em primeiro plano, mas também uma meditação sobre o quanto a militância e a clandestinidade interferiram numa mocidade que talvez fosse corriqueira.

Já o romance-reportagem, de modelo norte-americano, ficcionaliza eventos de impacto midiático, em geral na área da delinquência e da contravenção. Aqui podemos lembrar os nomes de José Louzeiro e de Percival de Souza. O primeiro escreveu aquele de maior êxito, $A$ infância dos mortos (1977), sobre meninos de rua e os maus-tratos de que são vítima. Transposto para o cinema por Hector Babenco, como Pixote: a lei do mais fraco (1980), faria carreira internacional e tornaria seu autor famoso.

Como seu nome indica, o romance-reportagem desenvolve um discurso praticamente indiscernível do jornal: sensacionalismo, ângulo de terceira pessoa, linguagem desataviada e que não evita o lugar-comum etc. 
Embora posteriormente suplantado pelo biografismo, o gênero continua atual. Drauzio Varella - autor de Estação Carandiru, que vendeu 470.000 exemplares ficou famoso e ganhou talk-show na televisão. Viria a se tornar uma autoridade midiática em assuntos de saúde.

Alguns traços do memorialismo e do romance-reportagem permeariam o biografismo, que assim ficou contaminado por ambos. Do memorialismo, a experiência pessoal: os autores não estão registrando suas próprias vidas, mas vidas com as quais se identificam, que fazem parte de sua experiência vicária e que aprovam, de uma maneira ou de outra. Do romance-reportagem: ao fazer uma biografia, cercam uma área e tratam de investigá-la minuciosamente, inventariando sua cartografia social e humana.

Se indagarmos quais são os marcos do novo biografismo, logo identificaremos Olga, de Fernando Morais, que vendeu 170.000 exemplares só na reedição pela Companhia das Letras, sem contar a edição original pela Alfa Ômega. Segue-se a profissionalização do autor, paralelamente à de Rui Castro, ambos tendo escrito já perto de uma dúzia desses livros cada um. Entre as deste último, as de Garrincha, Nelson Rodrigues, Carmen Miranda. De Fernando Morais, a mais recente é a de Paulo Coelho.

Dois traços, perdidos na sequência, definem os inícios do novo biografismo: em primeiro lugar, versaria as vidas pouco divulgadas ou de brasileiros ou de pessoas de interesse crucial para a história do Brasil; em segundo, defenderia causas progressistas. Detecta-se a necessidade de urdir a crônica dos tempos próximos, enquanto o recuo azado à historiografia demorasse a se instalar. $O$ fato de alguns deles terem-se tornado best-sellers foi uma benesse a mais. Essas narrativas não se transformam propriamente em ficção, mantendo antes uma voz neutra e objetiva, mais próxima do jornalismo, não escondendo seu parentesco com a crônica.

Acrescente-se que tais livros são bem menos sisudos que as biografias oficiais, em geral panegíricas, ou as teses. Descartam uma certa solenidade, típica do gênero; em contrapartida, por vezes acolhem versões fantasiosas, pouco comprováveis. Mas o fato de seus autores serem jornalistas, mestres de uma escrita fluente e vivaz, sem dificuldades de leitura, além de incorporarem técnicas ficcionais como o monólogo interior ou o flashback, ou ainda a reconstituição puramente imaginária de diálogos, torna indistintas as fronteiras entre os dois domínios.

As editoras farejaram o maná e meia-dúzia delas se lançaram à fabricação de biografias apressadas. Como por exemplo uma coleção sobre personalidades mais ou menos conhecidas do entretenimento, cada volume delgado tendo por base um depoimento de três horas do próprio biografado. 
Ao que tudo indica, a evolução do jornalismo vem expulsando da página impressa profissionais veteranos, especialmente aqueles mais ligados ao campo cultural, que então empregam seus talentos em programas de televisão, em revistas eletrônicas ou no biografismo. A isso associa-se a expansão do mercado editorial nos anos 1990, quando proliferaram as pequenas editoras, elevando o total dessas empresas no país a cerca de 500, na estimativa da Câmara Brasileira do Livro. Dentre elas, umas 50 maiores controlam $70 \%$ do mercado, sobrando uma pequena parcela para as muitas outras. Trata-se de um mercado nada desprezível, já que seu volume de negócios, embora menor quando comparado ao das línguas dominantes, é da ordem de dois bilhões de dólares, classificando-o como o décimo do mundo.

O êxito de mercado e as altas tiragens que tais livros alcançam obrigam à cogitação de que seu condão possa beneficiar-se de ainda outro ingrediente ficcional. De fato, parece ter migrado para o biografismo aquilo que tornava atraente o romance oitocentista, ao privilegiar um herói e os anos de sua formação, e que acabou por desaparecer no século seguinte, quando as vanguardas tenderam a eliminar o enredo. Dessa maneira, a fiç̧ão abria as comportas para a vivência vicária, preenchendo funções psicológicas e sociais valiosas, cujas virtualidades parecem ter-se refugiado hoje nas modalidades biográficas. Enquanto isso, nos catálogos das editoras diminui o número de romances e aumenta o de biografias.

\section{Protagonistas}

Vejamos de quem tratam essas numerosas biografias. Adianto aqui alguns nomes. Em primeiro lugar, e disparado, confirma-se a posição fora do comum que a música popular ocupa na vida dos brasileiros: a maior frequência é de figuras ligadas a essa área. Já ganharam livros Pixinguinha, Ary Barroso, Lamartine Babo, Baden Powell, Mário Lago, Luiz Gonzaga, Cazuza, Cauby Peixoto, João Gilberto, Aracy de Almeida, João do Vale, Orlando Silva, Elis Regina, Chiquinha Gonzaga, Nássara, Orestes Barbosa, Nelson Cavaquinho, Monarco, Zeca Pagodinho, Renato Russo, Zé Kéti, Wilson Batista, Chico Buarque, o Clube da Esquina e a Bossa Nova. Dentre os eruditos, Villa-Lobos. Os mais populares e pitorescos receberam até mais de um, como é o caso de Noel Rosa, Carmen Miranda, Tom Jobim, Vinicius de Moraes e Adoniran Barbosa.

Em segundo lugar, os holofotes iluminam a cena política. E nela, os profissionais, como Ulysses Guimarães, Carlos Lacerda, Gustavo Capanema, Oswaldo Aranha. Ou Gregório Fortunato, o guarda-costas de Getúlio Vargas, estopim de sua ruína. 
Ou pessoas de projeção com alcance político, como D. Helder Câmara e Sobral Pinto. Cortando o passo aos biógrafos, D. Paulo Evaristo Arns, como os dois anteriores figura de proa na resistência à ditadura, produziu em 2000 sua autobiografia. Ganham destaque os presidentes da República, como Getúlio Vargas, Juscelino Kubitschek, marechal Castello Branco, Tancredo Neves, Fernando Henrique Cardoso e Luiz Inácio Lula da Silva. Estes dois foram até agraciados com um mesmo livro, que coteja a vida de ambos. Em terceiro lugar, num gênero em que o monopólio da autoria cabe aos jornalistas, estão os próprios jornalistas, seguidos por personalidades de palco ou tela. Entre os primeiros, Chateaubriand, Davi Nasser, Samuel Wainer, Paulo Francis, Nelson Rodrigues, Roberto Marinho: por enquanto só os mais espetaculares ou polêmicos. Os de palco ou tela, mina que mal começa a ser explorada, já têm Glauber Rocha, Dercy Gonçalves, Cacilda Becker, Cleide Yaconis, Lélia Abramo, Procópio Ferreira, Ana Botafogo, Humberto Mauro, Anselmo Duarte, Mazzaropi, Ruth de Souza, ou um apresentador de Tv como Sílvio Santos. Sem contar as inúmeras que têm surgido nas novas e apressadas coleções que focalizam gente de telenovela.

Constituem exceções as biografias de alguém menos bafejado pela mídia e fora desses três grupos, entre eles Portinari, Tarsila do Amaral, Pagu, Carlos Drummond de Andrade, Lota Macedo Soares (com Elizabeth Bishop), Pedro Nava. Infelizmente, as biografias literárias estão nesse caso. Afora personalidades que imantam os trabalhos, como Machado de Assis, Euclides da Cunha e Lima Barreto, poucas há, e não seduzem as teses universitárias, embora ultimamente surjam indícios de retomada. Oswald de Andrade, Cecília Meireles, Mário Faustino estão entre os raros contemplados nos últimos tempos, enquanto Clarice Lispector tem recebido várias. Mas alguns dos mais relevantes escritores de tempos anteriores ainda aguardam o privilégio.

\section{Destino das biografias}

É de notar que o novo biografismo, bem mais que o romance, constitui uma fonte para o cinema e a televisão que ainda está longe de se esgotar, em adaptações para filmes de ficção, documentários, docudramas, telefilmes e séries televisivas, alimentando outros circuitos da indústria cultural. Paralelamente, nota-se um desenvolvimento extraordinário da cinebiografia documentária, exibida com frequência na televisão, em formato de meia ou uma hora, quando não do tamanho de um longa-metragem normal. E não só os óbvios, como Santos Dumont, Glauber Rocha, Mário de Andrade, Lampião, Juscelino Kubitschek, Jango Goulart, Getúlio Vargas, 
Jânio Quadros, Teotônio Vilela, Carlos Drummond de Andrade, até figuras esquivas como Sousândrade. Não é de estranhar o nível de excelência que alcançaram nossos documentários, arrebatando prêmios e público, ao constituir um terço dos filmes realizados. Registre-se que Cabra marcado para morrer, clássico dirigido por um dos mais reputados documentaristas, Eduardo Coutinho, é uma biografia, a da militante Elizabeth Teixeira, viúva de um líder das Ligas Camponesas de Pernambuco. Já a cinebiografia ficcional é de há muito um gênero profícuo em Hollywood, com maior ênfase nas personalidades do mundo musical - cantores, compositores, bailarinos, instrumentistas etc. -, mas incursionando por outras áreas, como os esportes e a política. No Brasil, sublinhando a vertente e confirmando o fascínio que a vida dos outros exerce, dois campeões nacionais de bilheteria foram justamente cinebiografias. Cazuza e Olga atraíram cada um três milhões de espectadores, o que não é pouco em comparação ao campeão absoluto, Homem Aranha, com oito milhões. Ademais, ficaram entre os dez mais assistidos.

Nisso, as biografias suplantam a literatura conspícua. Por isso mesmo, seus autores não são basicamente escritores de literatura do tipo tradicional, mas antes jornalistas, desdobrados em roteiristas de cinema e televisão, bem como autores de telenovela, o que certamente pesa sobre a maneira de escrever. Acresce que são vigorosas e interessantes, enquanto os romances e contos andam meio repetitivos.

Esbocei aqui os delineamentos, talvez um tanto esquemáticos, de um livro anterior. Minha proposta é que se avalie o romance brasileiro contemporâneo nos contextos nacional e internacional. Para compreender a busca de identidade desse romance, é necessário levar em conta a eclosão da biografia. Para precisar o que para nós significa neste momento a questão da identidade postulada pelo romance, é bom atentar para a fonte da preocupação com identidade, que não é a mesma dos séculos passados. E, mais uma vez, sugiro que se recuse a etiqueta de "pós-colonial" quando aplicada à literatura de nações que são independentes há perto de dois séculos, a exemplo do Brasil e dos países da América Espanhola.

Walnice Nogueira Galvão é professora titular da Universidade de São Paulo, visiting scholar da Columbia University e professora visitante da Université de Paris vin e da University of Texas System. É autora de Euclidiana: ensaios sobre Euclides da Cunha (Companhia das Letras, 2009); Mínima mímica (Companhia das Letras, 2008); Tapete afegão (Companhia das Letras/ Nacional, 2008); A donzela guerreira: um estudo de gênero (Senac, 1998), entre outros.

80. GALVÃO, Walnice Nogueira. Sobre estratégias identitárias 